\title{
Implementation of high performance liquid chromatography coupled to thermal lens spectrometry (HPLC-TLS) for quantification of pyranoanthocyanins during fermentation of Pinot Noir grapes
}

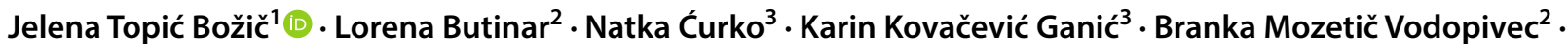 \\ Dorota Korte ${ }^{1} \cdot$ Mladen Franko $^{1}$
}

Received: 31 December 2019 / Accepted: 4 June 2020 / Published online: 9 June 2020

(c) Springer Nature Switzerland AG 2020

\begin{abstract}
In this work high performance liquid chromatography coupled to thermal lens spectrometry (HPLC-TLS) was applied for monitoring of vinylphenolic pyranoanthocyanins formation during the fermentation of Pinot Noir wines. Vinylphenolic pyranoanthocyanins are wine pigments, present in low concentrations, but very important for wine colour stability. Fermentation process was conducted with four different yeast strains, used as starters, either in sequential fermentation of non-Saccharomyces with S. cerevisiae yeast or as single fermentation with S. cerevisiae yeasts in order to test the applicability of developed method for monitoring of selected compounds in real wine fermentation experiments. The developed HPLC-TLS method showed higher sensitivity compared to HPLC coupled to diode array detection (DAD) technique for particular wine colour compounds. Obtained limits of detection (LODs), were 6- and 22-times lower in comparison to HPLC-DAD in gradient and isocratic elution mode, respectively, whereas limits of quantification (LOQs) 5 and 18-times lower. Lower LODs enabled earlier observation of vinylphenolic pyranoanthocyanins formation during fermentation (already at day 7) in the case of HPLC-TLS method in gradient mode, while by using HPLC-DAD in gradient elution mode the formation of vinylphenolic pyranoanthocyanins was noticed only after 12 days of fermentation.
\end{abstract}

Keywords Thermal lens spectrometry (TLS) · High performance liquid chromatography (HPLC) · Pyranoanthocyanins . Wine $\cdot$ Yeasts

\section{Introduction}

The colour of red wines is one of their most important sensorial characteristics. It results from the presence of anthocyanins, phenolic compounds that are extracted from grape skins during maceration and fermentation. The anthocyanins usually undergo different chemical changes already during the fermentation and also later during wine maturation and ageing $[1,2]$, however most of these changes go in the direction of non-desirable wine colour loss [3]. That is why numerous research efforts of wine chemists are directed towards finding new ways to preserve and/or improve wine colour, especially for the red wine cultivars that are known to be poor in colour $[4,5]$. Pyranoanthocyanins are currently acknowledged as one of the most important anthocyanin derivatives crucial for the stability of wine colour, especially for those wines that are known to be less rich in anthocyanin pigments such as

Electronic supplementary material The online version of this article (https://doi.org/10.1007/s42452-020-3005-8) contains supplementary material, which is available to authorized users.

Dorota Korte, dorota.korte@ung.si | 'Laboratory for Environmental and Life Sciences, Nova Gorica, Slovenia. ${ }^{2}$ Wine Research Centre, Vipava, Slovenia. ${ }^{3}$ Laboratory for Wine Technology and Analysis, Faculty for Food Technology and Biotechnology, University of Zagreb, Zagreb, Croatia. 
Pinot Noir (PN) wines [6-8]. One possible way of improving wine colour is through synthesis of pyranoanthocyanins, which can be formed with reaction of anthocyanins and yeast metabolites released during fermentation [9]. Compared to anthocyanins they are less susceptible to $\mathrm{pH}$ changes and $\mathrm{SO}_{2}$ decolouration $[10,11]$. There are three main types of pyranoanthocyanins found in wines; vitisins, vinylphenolic pyranoanthocyanins and pyranoanthocyanin-flavanols [12].

The synthesis of vinylphenolic pyranoanthocyanins takes place in the presence of yeasts as they transform grape hydroxycinnamic acids into reactive vinylphenols, which in turn condense with anthocyanins and form stable vinylphenolic pyranoanthocyanins. The transformation of hydroxycinnamic acids into reactive vinylphenols requires the presence of hydroxycinnamate decarboxylase enzyme (HCDC), an enzyme, which yeasts can possess, but the activity varies between species and strains a lot [13-17]. Furthermore, yeasts also influence other sensory properties like wine aroma and flavour, not only colour, emphasizing the role of detailed yeast characterization in the selection process of wine yeasts. Thus, the wine industry is focused on the development of new yeast strains or their combinations to improve the fermentation performance, as well as wine quality [18].

High performance liquid chromatography (HPLC) with gradient elution on $\mathrm{C} 18$ columns belongs to the group of the most widely used analytical techniques for anthocyanin and pyranoanthocyanin analysis. HPLC-VIS detection, photodiode array detection (HPLC-DAD), as well as mass spectrometry (HPLC-MS) or tandem mass spectrometry (HPLC-MS/MS) [15-17, 19-27] are conventionally used for detection of anthocyanins and pyranoanthocyanins in wines. Both HPLC-MS and HPLC-MS/MS provide sensitive and reliable tool for detection of anthocyanins and pyranoanthocyanins in the winemaking processes $[28,29]$. Unfortunately, they are expensive and not always available to the wine producers or researchers working in the field of wine yeast selection or fermentation. Reported LODs and LOQs from HPLC-VIS-DAD-MS/MS methods are evident from the Table 1. Thermal lens spectrometry (TLS) has already been proven to be sensitive analytical tool with low LODs (comparable to MS detection) with no sample preparation required for the analysis of other bioactive compounds in complex biological matrices [30, 31], making it potentially powerful tool for the analysis of pyranoanthocyanins in wine and wine-like solutions.

TLS belongs to a group of photothermal techniques and is based on the thermal lens effect first time reported in the 1964 [32]. Since then TLS technique found applications in analytical chemistry, physical chemistry, physics, biochemistry, etc. [31, 33-46]. It provides high sensitivity for detection of non-fluorescent analytes and enables analysis of small volume (sub $\mu \mathrm{L}$ ) samples as well as on-line detection in liquid chromatography and flow injection analysis. The application of TLS in chemical analysis is still not widespread due to the limited availability of laser sources, especially in the UV spectral region. Its main disadvantage is limited selectivity, however the problem can be overcome by coupling TLS to separation techniques such as HPLC $[37,47]$. Furthermore, TLS signal depends on the solvent's opto-thermal properties and is strongly affected by the changes in eluent composition. The resulting high level of baseline noise, caused by incomplete mixing of eluents considerably increases the LODs in gradient elution mode [48-50]. Thus, this technique is rarely used with gradient elution mode HPLC. However, the problem can be to some extent reduced by inserting a mixing coil or precolumn into the system, as mixing coil improves mixing of the eluents, resulting in decreased LODs [49]. HPLC-TLS has been previously used for determination of $\beta$-carotenes in blood plasma [51], fish oil-based supplementary drugs [52], and vegetable oils [53]. Furthermore, HPLC-TLS has found application in determination of bilirubin and biliverdin in blood serum [30, 31], offering 50-100 (200) times lower limit of detection compared to HPLC-DAD [34, 38]. To the best of our knowledge, HPLC-TLS has not been yet applied for analysis of any anthocyanins or anthocyanin

Table 1 LOD/LOQs values of different HPLC/LC/UHPLC methods for analysis of anthocyanins and pyranoanthocyanins in wine or grape skin samples

\begin{tabular}{|c|c|c|c|c|}
\hline Method & Sample type & LOD & LOQ & References \\
\hline$\mu \mathrm{HPLC}-\mathrm{MS} / \mathrm{MS}$ & $\begin{array}{l}\text { Different anthocyanins and pyranoanthocyanins in } \\
\text { diluted wine (expressed as Mvd-3-glc equivalents) }\end{array}$ & $0.221-0.604 \mu \mathrm{g} / \mathrm{L}$ & $0.274-1.157 \mu \mathrm{g} / \mathrm{L}$ & {$[25]$} \\
\hline HPLC-DAD & Mvd-3-glc standard & $0.41 \mu \mathrm{g} / \mathrm{mL}$ & $1.24 \mu \mathrm{g} / \mathrm{mL}$ & {$[27]$} \\
\hline HPLC-DAD & Mvd-3-glc standard & $0.15 \mathrm{mg} / \mathrm{L}$ & $0.55 \mathrm{mg} / \mathrm{L}$ & [19] \\
\hline LC-MS & $\begin{array}{l}\text { Mvd-3-glc } \\
\text { standard }\end{array}$ & $9 \mathrm{ng} / \mathrm{mL}$ & $27 \mathrm{ng} / \mathrm{mL}$ & {$[24]$} \\
\hline$\mu \mathrm{HPLC}-\mathrm{PDA}$ & Mvd-3-glc standard & $0.10 \mathrm{mg} / \mathrm{kg}$ & $0.31 \mathrm{mg} / \mathrm{kg}$ & {$[20]$} \\
\hline HPLC-VIS & Mvd-3-glc standard & $2.9 \mathrm{mg} / \mathrm{kg}$ & $8.9 \mathrm{mg} / \mathrm{kg}$ & {$[26]$} \\
\hline$\mu \mathrm{HPLC}-\mathrm{TQ}-\mathrm{MS}$ & Mvd-3-glc standard & $8 \mu \mathrm{g} / \mathrm{L}$ & $79 \mu \mathrm{g} / \mathrm{L}$ & [21] \\
\hline
\end{tabular}


derived components in red wines or in any other food of fruit origin or related studies.

The objective of this work was to develop a HPLC-TLS method for determination of vinylphenolic pyranoanthocyanins and use it to monitor the formation of vinylphenolic pyranoanthocyanins during production of Pinot Noir wines, as well as in characterization of micro scale wine yeasts fermentation processes (very low volume fermentation batches- $1.5 \mathrm{~mL}$ ). We aimed to test whether HPLC-TLC (compared to the HPLC-DAD routine method) would enable better sensitivity, along with successful identification and quantification of vinylphenolic pyranoanthocyanins in lower sample volumes, without any sample pre-concentration step of complex biological wine sample matrices. Moreover, the ability of non-Saccharomyces yeast cultures, used as starters to produce stable pigments called vinylphenolic pyranoanthocyanins was investigated. The monitoring of vinylphenolic pyranoanthocyanins' formation was performed in sequential fermentations of two non-Saccharomyces yeasts Pichia guilliermondii and Wickerhamomyces anomalus with two S. cerevisiae yeasts and single fermentations with S. cerevisiae yeasts in order to mimic the real fermentation processes and show the applicability of such analytical technique in wine chemistry and wine microbiology research experiments. The time of pyranoanthocyanin formation in fermentation procedure is important for new yeast strains characterisation in the processes of becoming a selected yeast inoculum. Since the new non-Saccharomyces yeast strains, already known to produce stable red wine pigments in higher extent, are usually not able to finish the fermentation of a wine, optimization of sequential yeast inoculations conditions for the best desired fermentation results (in this case colour of the end wine) are very important as well in this field. The results obtained by the application of the developed technique were compared to those provided by the use of isocratic and gradient HPLC-DAD method.

\section{Materials and methods}

\subsection{Materials}

HPLC grade methanol was purchased from J.T. Baker (Deventer, The Netherlands), citric acid $(\geq 99.5 \%)$, magnesium sulphate (anhydrous, $\geq 99.5 \%$ ), malic acid ( $\geq 99.0 \%$ ), p-coumaric acid $(\geq 98.0 \%$, , potassium phosphate monobasic (for molecular biology, $\geq 98.0 \%$ ), tartaric acid ( $\geq 99.5 \%)$, and trifluoroacetic acid (Reagentplus ${ }^{\circ}, 99 \%$ ) were purchased from Sigma-Aldrich (Steinheim, Germany). Calcium chloride dihydrate $(\geq 99.0 \%)$ and glucose (for biotechnology) were purchased from VWR (Wien, Austria). Fructose $(\geq 99.0 \%)$ was purchased from Alfa Aesar (Kandel,
Germany). Double deionized water $\left(\mathrm{ddH}_{2} \mathrm{O}\right)$ was used for preparation of all aqueous solutions (18.2 MOhm, ELGA LabWater, High Wycombe, UK). Malvidin-3-O-glucoside standard ( $\geq 95.0 \%$ ) was purchased from Extrasynthese (Genay, France). $100 \mathrm{mg} / \mathrm{L}$ stock solution of malvidin-3-Oglucoside standard was prepared in methanol and stored at $-20^{\circ} \mathrm{C}$. Prior to the analysis appropriate volume of malvidin-3-O-glucoside stock solution was evaporated to dryness using Genevac ${ }^{\mathrm{TM}}$ miVac centrifugal concentrator (Ipswich, UK) and reconstituted in mobile phase A $(0.2 \%$ trifluoroacetic acid in $\mathrm{ddH}_{2} \mathrm{O}$ ) in order to prepare standard solutions for calibration.

\subsection{Wine fermentation sample preparation}

We have prepared two types of samples; synthetic wine must samples and real samples taken during fermentation of Pinot Noir grapes. Synthetic wine must samples were prepared as described in the Sect. 2.3.3 in order to have controlled conditions of pyranoanthocyanin synthesis for optimization of the HPLC-TLS method. After optimization of developed HPLC-TLS method, experiment with a lab-scale Pinot Noir grape fermentation was conducted and samples were taken and analyses at different days of fermentation process. Lab-scale wine fermentation procedure is described in detail in the Sect. 2.4.

\subsubsection{Preparation of yeasts for fermentation experiments}

Native Saccharomyces cerevisiae and non-Saccharomyces yeasts with high pyranoanthocyanin formation potential were selected based on previously published study by Topić Božič et al. [54]. Therefore, two Saccharomyces cerevisiae strains were used, Fermol Premier Cru (FPC) (commercial strain, AEB Group, Italy) and ZIM2180 (native strain). Among the non-Saccharomyces strains Pichia guilliermondii ZIM624 and Wickerhamomyces anomalus S138 were chosen for experiments. According to Topić Božič et al. [54], yeasts were streaked from cryo-cultures, stored in 15\% glycerol in in-house yeast collection, onto Wallerstein Lab (WL) plates and incubated for $48 \mathrm{~h}$ at $25^{\circ} \mathrm{C}$. Thereafter, pre-cultures were prepared by inoculating colonies from WL plates into $50 \mathrm{~mL}$ of YPD (composed of $1 \%(\mathrm{w} / \mathrm{v}$ ) yeast extract, $2 \%(\mathrm{w} / \mathrm{v})$ peptone, $2 \%(\mathrm{w} / \mathrm{v})$ glucose) medium in $250 \mathrm{~mL}$ sterile Erlenmeyer flasks. Pre-cultures were incubated for $24 \mathrm{~h}$ at $25^{\circ} \mathrm{C}$ with shaking at $250 \mathrm{rpm}$. Optical density (absorbance at $600 \mathrm{~nm}$ ), determined by UV-Vis spectrophotometer (Perkin-Elmer, Lambda, Waltham, Massachusetts, USA) (OD600) of washed pre-cultures was checked and adjusted to OD $600=1$ with $0.85 \%$ sterile saline solution, if necessary. The final OD600, i.e. concentration of yeast inoculum in lab-scale fermentations was unified among experiments and set to be $0.1 \mathrm{AU}$. 


\subsection{Micro-fermentation samples}

\subsubsection{Preparation of synthetic grape must (SGM)}

SGM media was prepared according to Henscke and Jiranek [55] with some modifications. Briefly, SGM medium was made from fructose and glucose in the ratio $1: 1$, tartaric acid, malic acid, citric acid, $\mathrm{KH}_{2} \mathrm{PO}_{4}, \mathrm{MgSO}_{4}$, $\mathrm{CaCl}_{2}{ }^{*} 2 \mathrm{H}_{2} \mathrm{O}$, vitamins, trace minerals and amino acids. The $\mathrm{pH}$ of SGM was adjusted to 3.5 to mimic the $\mathrm{pH}$ of wine. Stock solutions of amino acids, trace minerals and vitamins were prepared in $\mathrm{ddH}_{2} \mathrm{O}$ and filtered through sterile 0.22 $\mu \mathrm{m}$ PES filter (VWR, Austria) and kept at $4{ }^{\circ} \mathrm{C}$.

\subsubsection{Pinot Noir skin extract preparation}

PN grapes were collected at the harvest in 2017 from a wine estate in the Vipava valley in Slovenia. Skins of PN grapes were manually peeled from the berries and lyophilized (Kambič Lio5pb, Slovenia). Following lyophilization, skins were ground in liquid $\mathrm{N}_{2}$ and stored at -20 ${ }^{\circ} \mathrm{C}$. Extraction of anthocyanins from ground skins was as followed: To $1 \mathrm{~g}$ of ground skin, $20 \mathrm{~mL}$ of methanol was added. The solution was ultrasonicated for $15 \mathrm{~min}$ and afterwards centrifuged (Eppendorf 5804, Hamburg, Germany) for $5 \mathrm{~min}$ at $6000 \mathrm{rpm}$. The procedure was repeated four times and supernatant was pooled together. Methanol extract was evaporated to dryness using rotary evaporator (Büchi Laborota 4000, Flawil, Switzerland) $\left(25^{\circ} \mathrm{C}, 90\right.$ rpm) and dry leftover was stored at $-80^{\circ} \mathrm{C}$ until further use in the fermentation experiments.

\subsubsection{Formation of vinylphenolic pyranoanthocyanins in synthetic wine}

The PN skin extract dried leftover (extraction procedure is described in the Sect. 2.3.2) was reconstituted in $80 \mathrm{~mL}$ of synthetic grape must (SGM) which was in turn filtered through sterile $0.22 \mu \mathrm{m}$ PES filter (VWR, Austria). Initial concentration of total anthocyanins in filtered synthetic grape must was determined with HPLC-DAD (Sect. 2.5) and was $93 \mathrm{mg} / \mathrm{L}$ (expressed as malvidin-3-glucoside equivalents). Fermentations with S. cerevisiae FPC yeast were carried out in deep well microtiter plates using synthetic grape must with PN skin extract or synthetic grape must with $50 \mathrm{mg} / \mathrm{L}$ of malvidin-3-O-glucoside. To the synthetic must solution, a $p$-coumaric acid was added as well in such amount that its final concentration reached $50 \mathrm{mg} / \mathrm{L}$. This medium (1.35 $\mathrm{mL}$ ) was distributed into deep well microtiter plates. FPC yeast culture was inoculated into the medium $(150 \mu \mathrm{L})$. The deep well plate was covered with sterile cover to prevent evaporation. The fermentation spanned for 10 days and was performed in four replicates.

\subsection{Lab-scale wine fermentation}

Wine fermentations were performed according to standard technological protocol for red winemaking [56], while yeast inoculation strategy was following the one already described by Topić Božič et al. [54]. Fresh Pinot Noir grapes were destemmed and crushed. The fermentations were performed in four replicates in $1 \mathrm{~L}$ volumetric flasks with fermentation caps. The fermentation caps were punched twice daily and all treatments were macerated for 7 days. After 7 days, the wine was pressed and fermented until the concentration of sugars reached concentrations lower than $2 \mathrm{~g} / \mathrm{L}$ which was determined spectrophotometrically (Perkin-Elmer, Lambda, Waltham, Massachusetts, USA) with D-Fructose/D-Glucose Assay Kit enzymatic kit from Megazyme (Madrid, Spain) according to producer instructions. Six different experiments (i.e. fermentations) were performed with four different yeasts either as single fermentations of S. cerevisiae yeasts, or sequential fermentations of non-Saccharomyces with Saccharomyces yeasts (FPC, ZIM2180, S138 + FPC, ZIM624 + FPC, S138+ ZIM2180, ZIM624 + ZIM2180). In the case of sequential fermentations, firstly non-Saccharomyces yeast was inoculated and at the day three of fermentation process, S. cerevisiae yeast was inoculated. Fermentation with single yeast inoculation lasted for 16 days, while sequential fermentations spanned for 21 days. After fermentations the wines were clarified and racked. Prior to bottling, $50 \mathrm{mg} / \mathrm{L}$ of free $\mathrm{SO}_{2}$ was added in the form of $\mathrm{H}_{2} \mathrm{SO}_{3}(5-6 \%(\mathrm{v} / \mathrm{v}))$ according to manufacturer instructions (Agrolit, Litija, Slovenia). During fermentation, sampling was performed at day 2, 7, 12 and at the bottling day (day 16 for single culture fermentation and day 21 for sequential fermentation) in order to follow the evolution of pyranoanthocyanins in real grapevine fermentations.

\subsection{Quantification and identification of anthocyanins and pyranoanthocyanins in fermentation and wine samples}

\subsubsection{HPLC-DAD}

The compounds were analysed using Agilent Technologies 1100 system (Palo Alto, California, USA) HPLC chromatograph equipped with a quaternary pump, an autosampler and photo-diode array detector. Gradient elution of mobile phase $A(0.2 \%$ trifluoroacetic acid in water) and mobile phase $B(0.2 \%$ trifluoroacetic acid in methanol) was used. Gradient elution was as follows: 0 min 20\% B, 0-20 $\min 20-45 \%$ B, 20-30 min 45-55\% B, 30-40 min 55-70\% $B, 40-50$ min equilibration to initial conditions with initial eluent flowing through the column ( $80 \%$ A, 20\% B). Injection volume was $40 \mu \mathrm{L}$. The column used for separation 
was reverse-phase Phenomenex Luna C18 PFP(2) $(250 \times 4.6$ $\mathrm{mm}, 5 \mu \mathrm{m}$ i.d.) with matching guard column (Phenomenex, Torrance, USA). The column temperature was set to $25^{\circ} \mathrm{C}$. Wavelength used for detection was $520 \mathrm{~nm}$. Quantification was performed using malvidin-3-O-glucoside (Mvd-3-glc) (Extrasynthese, France) as external standard. Anthocyanins and pyranoanthocyanins were quantified and expressed as Mvd-3-glc equivalents.

\subsubsection{HPLC-TLS}

HPLC coupled to TLS detection was performed using an HPLC pump (Knauer Smartline pump 1000, Germany), Rheodyne manual injector (model 7725i) (Bensheim, Germany), $8 \mu \mathrm{L}$ flow-through detection cell with $1 \mathrm{~cm}$ optical path length (Hellma, model 178.173-QS, Müllheim, Germany) and a dual-beam TLS detection system. The experimental set-up is schematically presented in the Fig. 1. In each chromatographic run a $20 \mu \mathrm{L}$ of sample or standard solution was injected manually. Step-gradient elution (initially mobile phase $\mathrm{A}(0.2 \%$ trifluoroacetic acid in water) and mobile phase $B(0.2 \%$ trifluoroacetic acid in methanol) in 70/30 (mobile phase $A$ /mobile phase $\mathrm{B}$ ) volume ratio, followed by $60 / 40 \mathrm{~A} / \mathrm{B}$ after elution of malvidin-3-O-glucoside at $5 \mathrm{~min}$ ). Time of analysis was $20 \mathrm{~min}$, followed by column equilibration to the initial conditions. The column used for separation was the reverse-phase Phenomenex Luna C18 PFP(2) (250x4.6 $\mathrm{mm}, 5 \mu \mathrm{m}$ i.d.) with matching guard column (Phenomenex, Torrance, USA). Pyranoanthocyanin determination was accomplished using a dual-beam mode-mismatched thermal lens spectrometer. The excitation beam (EB) originating from an argon ion laser tuned to $514.5 \mathrm{~nm}$ (Innova 70, Coherent, providing $350 \mathrm{~mW}$ power, Palo Alto, California, USA) and modulated by a mechanical chopper (Control Unit 300C, chopping head 300CD, chopping discs $300 \mathrm{H}$, Scitec Instruments, Trowbridge, UK) at $24 \mathrm{~Hz}$, that provided the maximum signal to noise ratio, was focused onto the sample using a $70 \mathrm{~mm}$ focal length lens (Edmund Optics, York, UK). As a result of EB energy loss when reflection from the mirrors, its power was reduced to the value of $160 \mathrm{~mW}$ at the location of the flow-through detection cell. The probe beam PB $(623.8 \mathrm{~nm})$ originated from a $2 \mathrm{~mW}$ helium neon-laser (Melles Griot, Uniphase, Model 1103P, Carlsbad, California, USA) was focused by a $25 \mathrm{~mm}$ diameter lens of 70 $\mathrm{mm}$ focal distance (Edmund Optics, York, UK) to have its waist placed at $3^{1 / 2}$ times the confocal distance beyond the sample, what ensures the condition for achieving maximum TLS signal [31].

Collinear propagation of the excitation and probe beams was achieved with a dichroic mirror (Melles Griot, Carlsbad, California, USA), which directed both beams through the flow-through cell. The changes in the probe-beam intensity were monitored by a photodiode (Thorlabs, model PDA 36A-EC, Newton, New Jersey, USA) equipped with an interference filter $(633 \mathrm{~nm}$, Thorlabs, model PDA 36A-EC, Newton, New Jersey, USA), connected to a lock-in amplifier (Stanford Research Instruments, model SR830 DP, Sunnyvale, USA) which

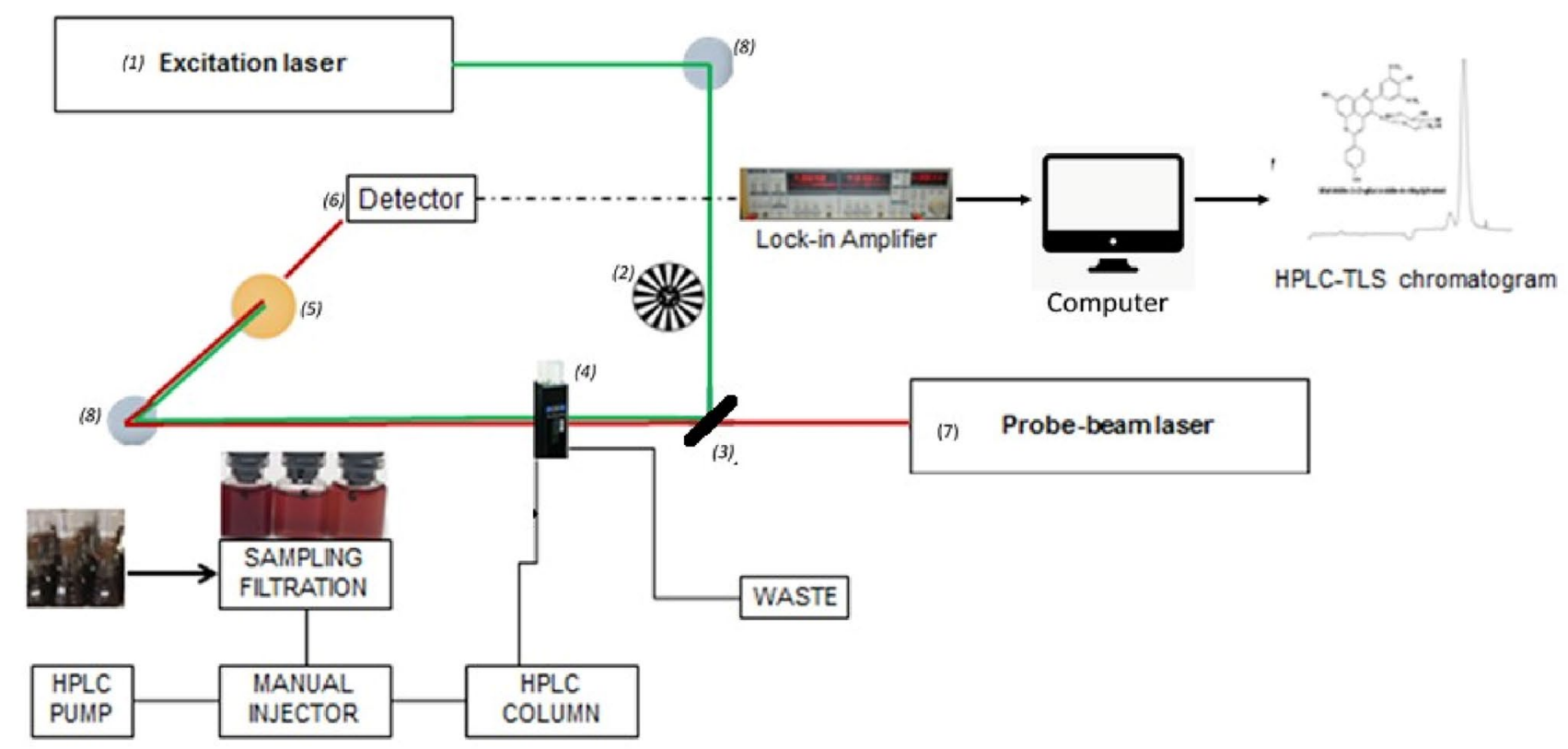

Fig. 1 Schematic presentation of dual-beam HPLC-TLS experimental setup. Legend: excitation laser (1); chopper (2); dichroic mirror (3); flowthrough cell (4); interference filter (5); photodiode (6); probe beam laser (7), mirrors (8) 
amplified only the components of the input signal that appeared with the frequency of the reference signal.

\subsubsection{Identification of pyranoanthocyanins}

Since commercial standards of pyranoanthocyanins are still not available, vinylphenolic pyranoanthocyanins were synthesized and isolated using semi-preparative HPLC-DAD [57] for the purpose of pyranoanthocyanin identification. The synthesis was focused on the three main vinylphenolic pyranoanthocyanins detected in wines $[12,15]$.

Vinylphenolic pyranoanthocyanins were obtained by fermentation of synthetic must containing Pinot Noir grape skin anthocyanins in presence of yeast that exhibit high hydroxycinnamate decarboxylase (HCDC) activity. Produced pyranoanthocyanins were isolated using Agilent Infinity 1260 HPLC-DAD (Agilent Technologies, Palo Alto, California, USA) operating in a semi-preparative mode. Separation column used was Zorbax Pursuit 5 C18, $250 \times 10 \mathrm{~mm}$ (Agilent Technologies, Agilent Technologies, Palo Alto, California, USA). Isolated pyranoanthocyanins were identified using UHPLC-DAD-MS system (Accela 1250 coupled to an LTQ Velos MS, Thermo Fisher Scientific, Waltham, MA, USA). Gradient elution of mobile phase A ( $2.2 \%$ formic acid in $\left.\mathrm{dd}_{2} \mathrm{O}\right)$ and mobile phase $\mathrm{B}(2.2 \%$ formic acid, $85 \%$ acetonitrile and $12.8 \% \mathrm{dd}_{2} \mathrm{O}$ ) was applied the

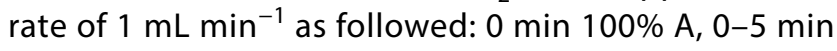
$10 \%$ B , 5-20 min 10-35\% B, 20-22 min 35\% B, 22-26 min $35-45 \%$ B, 26-27 min 45-60\% B, 27-32 min equilibration to initial conditions. The column used was Kinetex EVO C18 $(250 \times 4.6 \mathrm{~mm}, 5 \mu \mathrm{m}$ i.d. $)$ with matching guard column (Phenomenex, Torrance, USA) with set temperature at $40^{\circ} \mathrm{C} .20 \mu \mathrm{L}$ of sample was injected into the HPLC. The HESI parameters were: heater temperature $400^{\circ} \mathrm{C}$, drying gas $\left(\mathrm{N}_{2}\right)$, sheath gas flow rate 60 a.u. (arbitrary units), auxiliary gas flow rate 10 a.u., sweep gas flor rate 2 a.u., spray voltage $3 \mathrm{kV}$, transfer capillary temperature $350^{\circ} \mathrm{C}$. Mass spectrometry was performed in the positive scan mode (scan range $m / z$ 250-1200). Fragmentation of precursor ions was performed with a normalized collision energy of 35\% [57].

The identities of isolated pyranoanthocyanins, MS, UV-Vis spectral data and HPLC-TLS retention times are presented in the Table 4. MS ${ }^{n}$ fragments of isolated pyranoanthocyanins are presented in the supplementary information. The isolated compounds served in HPLC-DAD and HPLC-TLC measurements as standards for identification purposes.

\section{Results}

\subsection{Preliminary TLS measurements and selection of mobile phase composition}

In the case of TLS detection, the implementation of gradient elution has proven to be less favourable with respect to limits of detection. During gradient elution, eluent composition and with it optothermal properties of the eluent change, which can generate strong local gradients of refractive indexes within the eluent due to incomplete mixing. This affects TLS signal, resulting in major fluctuations of baseline noise and subsequently higher LOD values $[49,50]$. Therefore, isocratic elution was applied with $80 / 20,70 / 30,65 / 35$ and $60 / 40$ ratios of the solvent $A /$ solvent $B$ in the mobile phase with $1.00 \mathrm{~mL} / \mathrm{min}$ flow rate. The TLS enhancement factor contributed by the higher percentage of organic mobile phase (solvent B) was determined using the average of five chromatographic peak areas for $1 \mathrm{mg} / \mathrm{L}$ malvidin-3-O-glucoside and compared to calculated values according to Eq. 1:

$E=\left(-\frac{d n}{d T}\right) \frac{P}{k \cdot \lambda} \cdot \arctan \left(\frac{1}{\sqrt{3}}\right)$

where $E$ is the enhancement factor, $P$ power of the excitation source, $\lambda$ wavelength of the probe beam, $d n / d T$ is the temperature coefficient of refractive index, and $k$ is the thermal conductivity of the solvent $[58,59]$.

For the investigated mobile phases (composition A/B) the relative enhancements compared to the mobile phase consisting of $80 \%$ solvent $A$ and $20 \%$ solvent $B$ were calculated as the $A \mathrm{Aa}_{\mathrm{A} / \mathrm{B}} / \mathrm{Area}_{80 / 20}$. The $80 / 20$ composition had the lowest enhancement factor due to the highest content of water among the tested eluents. The experimentally obtained ratios were compared with theoretically calculated ratios for given eluent composition, i.e. $\mathrm{E}_{\mathrm{A} / \mathrm{B}} /$ $E_{80 / 20}$. The enhancement factors were calculated using thermooptical parameters $(d n / d T, \mathrm{k})$ for pure solvents [60] and Eq. (1). Approximate values of $d n / d T$ and $\mathrm{k}$ for eluents were calculated using Eq. (2) and Eq. (3), which are applicable to mixtures [61]:

$\frac{d n}{d T}=F_{1}\left(\frac{d n}{\partial T}\right)_{1}+F_{2}\left(\frac{d n}{\partial T}\right)_{2}$

Thermal conductivity ( $k$ ) for eluents used in this study was calculated with Filippov equation,

$k=F_{1} \cdot k_{1}+F_{2} \cdot k_{2}-0,72\left(k_{2}-k_{1}\right) \cdot F_{1} \cdot F_{2}$

where $\mathrm{F}$ is volume fraction of the pure solvent. The solvents included in the calculation were water and methanol as the most abundant constituents of the investigated 
eluents, therefore having the main influence on the enhancement of the signal. Trifluoroacetic acid was not used in the calculations due to being present in significantly lower concentration $(0.2 \%)$.

Chromatographic peak areas (Fig. 2) show the expected increase with decreasing volume fraction of water present in mobile phase due to higher temperature coefficient of the refractive index $(d n / d T)$ and lower thermal conductivity ( $k$ ) of organic solvent (i.e. methanol) in comparison to water [62-64]. The increase in the experimental enhancement factors with respect to enhancement factors for $\mathrm{A} / \mathrm{B}=80 / 20$ mobile phase composition $\left(\mathrm{E}_{\mathrm{A} / \mathrm{B}} / \mathrm{E}_{80 / 20}\right)$ is in agreement with theoretically predicted ratios of enhancement factors $\left(E_{A / B} / E_{80 / 20}\right)_{t}$ which also show increase with decreasing water volume fraction (Table 2). When comparing the signal of malvidin-3-O-glucoside when $80 / 20$ $\mathrm{A} / \mathrm{B}$ and $60 / 40 \mathrm{~A} / \mathrm{B}$ mobile phase are used, $70 \%$ increase in the signal of malvidin-3-O-glucoside can be observed with 60/40 A/B mobile phase (Fig. 3).

\subsection{Optimization of mobile phase composition for HPLC-TLC analyses}

Although the enhancement of the TLS signal was higher when $65 / 35$ and $60 / 40 \mathrm{~A} / \mathrm{B}$ eluents were used in our study, with these solvent systems we could not retain the anthocyanins on the column and Mvd-3-glc was eluted with the solvent front (Fig. 3). Since the quantification and calibration could not be done in such conditions, a 70/30 A/B mobile phase in the isocratic mode was selected for separation and detection of wine pigments with HPLC-TLS in further experiments.

However, under conditions of isocratic elution, separation of pyranoanthocyanin peaks from pigments in micro-fermentation experiment samples (synthetic wine fermented with commercial FPC yeast) was not possible. Therefore, step gradient was introduced with changing the
Table 2 Comparison of the ratios of malvidin-3-O-glucoside peak area $\left(\right.$ Area $\left._{\mathrm{A} / \mathrm{B}} / \mathrm{Area}_{80 / 20}\right)$ and the ratios of theoretically determined enhancement factors for investigated mobile phases

\begin{tabular}{lllll}
\hline$\% \mathrm{~A} / \mathrm{B}$ & $80 / 20$ & $70 / 30$ & $65 / 35$ & $60 / 40$ \\
\hline $\begin{array}{l}\left.\text { Area ( } \mathrm{V}^{*} \mathrm{~s}\right) \\
\begin{array}{c}\text { Enhancement } \\
\text { experimen- }\end{array}\end{array}$ & $0.27 \pm 0.03$ & $0.34 \pm 0.02$ & $0.43 \pm 0.01$ & $0.47 \pm 0.06$ \\
$\begin{array}{l}\text { tal } \mathrm{A}_{\mathrm{A} / \mathrm{B}} / \\
\mathrm{A}_{80 / 20}\end{array}$ & $1.26 \pm 0.02$ & $1.59 \pm 0.04$ & $1.72 \pm 0.02$ \\
$\begin{array}{c}\text { Enhancement } \\
\text { theoretical }\end{array}$ & & & & \\
$\mathrm{E}_{\mathrm{A} / \mathrm{B}} / \mathrm{E}_{80 / 20}$ & & 1.30 & 1.47 & 1.65 \\
\hline
\end{tabular}

mobile phase composition from $70 / 30 \mathrm{~A} / \mathrm{B}$ to $60 / 40$ right after the elution of Mvd-3-glc (Fig. 4) (at 5 min). The change in the eluent composition resulted in TLS signal fluctuation over a $30 \mathrm{~s}$ time frame, between retention times of 11 and $11.5 \mathrm{~min}$ as it is highlighted with the dashed-line red circle in Fig. 5, This signal fluctuation is not due to any photothermal effect, but is due to the change in the solvent composition which results in a non-uniform refractive index which distorts the probe beam and deflects it from its original propagation, as it was also reported earlier $[31,50]$. This is exhibited as a change in the signal because probe beam intensity at the detector changes, however it does not affect the detection of targeted pyranoanthocyanins as they elute after this change (Table 4).

\subsection{HPLC-TLS and HPLC-DAD method comparison}

The LODs and LOQs from HPLC-TLS and HPLC-DAD are presented in the Table 3. They were calculated for anthocyanin standard Mvd-3-glc as concentration providing a signal-to-noise ratio of 3 for LOD and 10 for LOQ [65]. The achieved LOD and LOQs values for HPLC-TLS method with $514.5 \mathrm{~nm}$ excitation beam were 6.5 times lower than
Fig. 2 The enhancement of chromatographic peak area for $1 \mathrm{mg} / \mathrm{L}$ malvidin-3-O-glucoside achieved by using higher percentage of solvent $B$

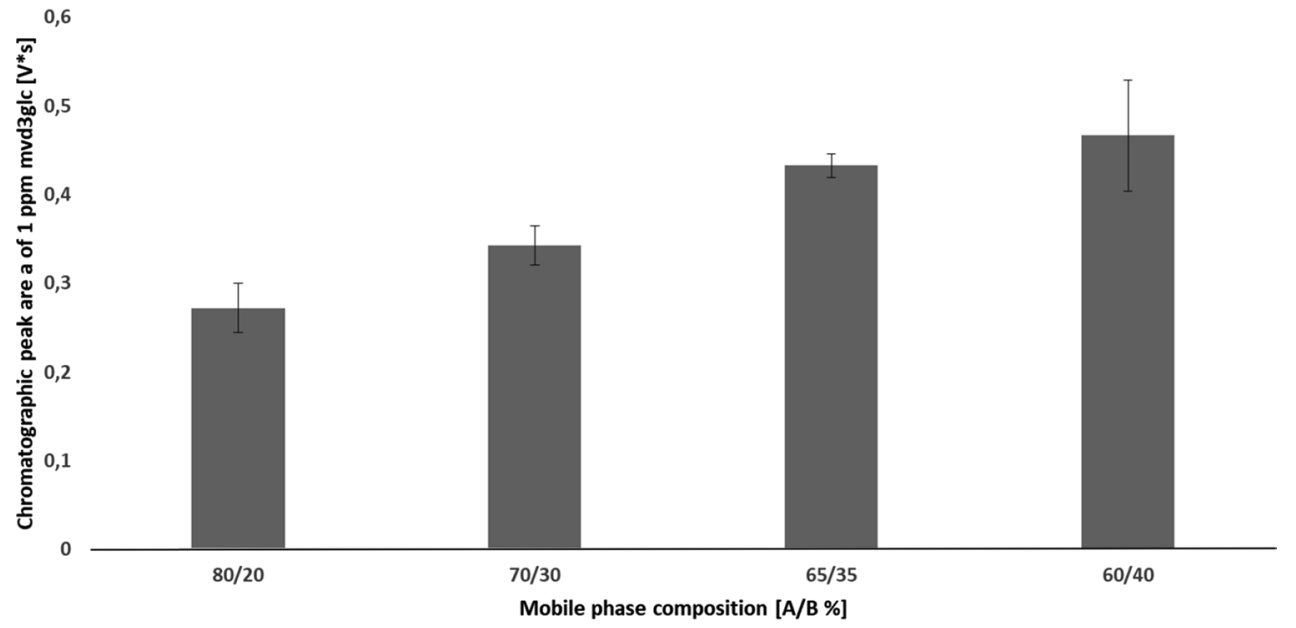

SN Applied Sciences A SPRINGER NATURE journa 

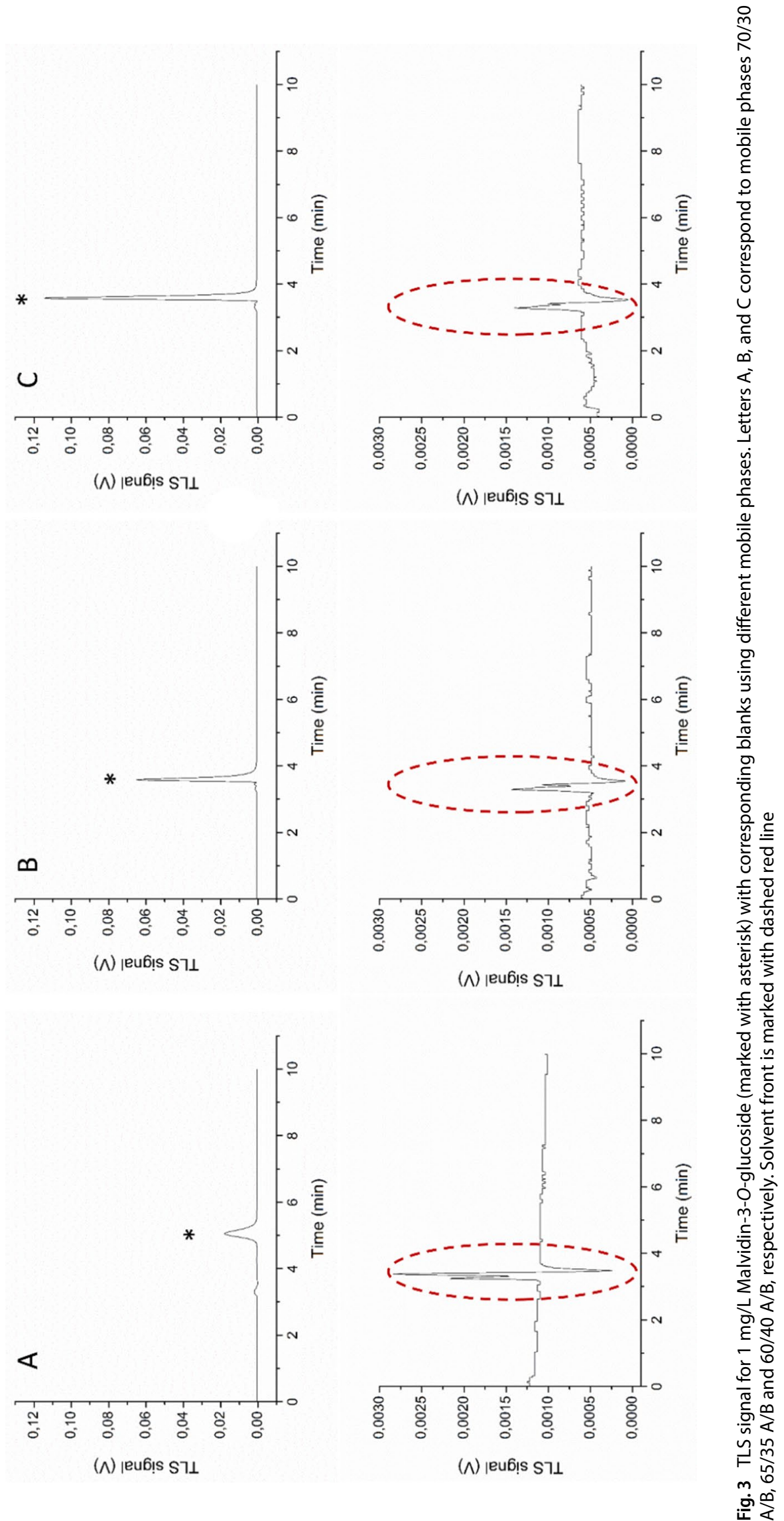

(^) |eu6!̣ sา $\perp$

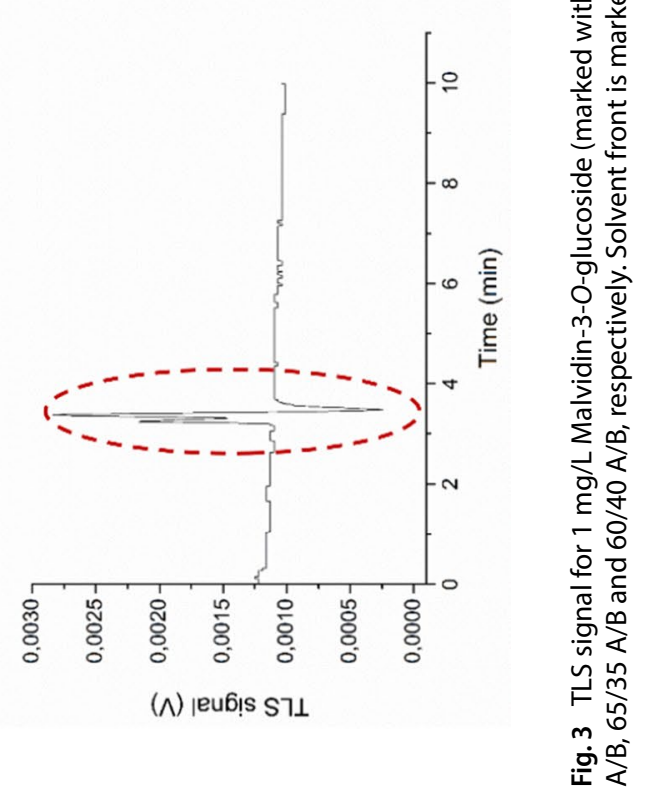




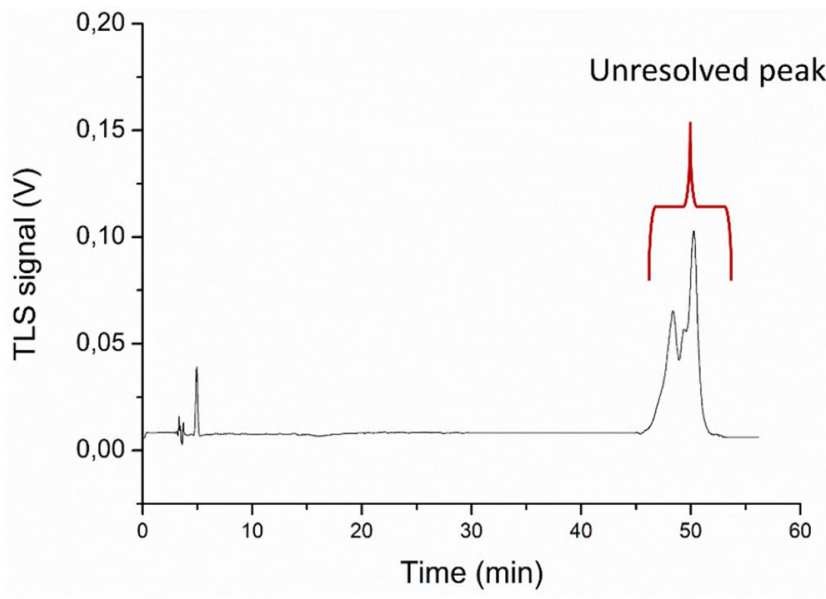

Fig. 4 HPLC-TLS chromatograms of synthetic grape must supplemented with $50 \mathrm{mg} / \mathrm{L}$ of malvidin-3-O-glucoside and $100 \mathrm{mg} / \mathrm{L}$ $p$-coumaric acid fermented with commercial FPC yeast using isocratic elution of $70 / 30 \mathrm{~A} / \mathrm{B}$ with marked unresolved peaks (left)

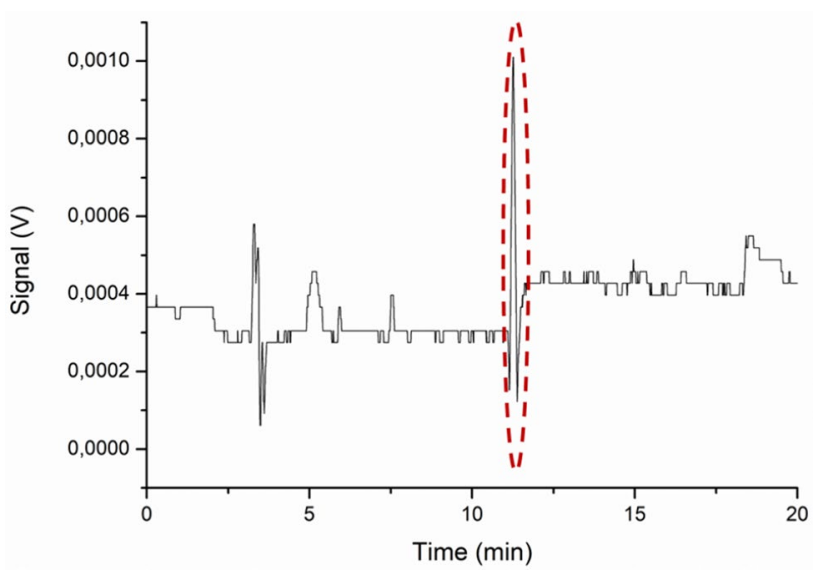

Fig. 5 HPLC-TLS chromatogram of a blank sample (mobile phase A- $0.2 \%$ trifluoroacetic acid in water) using step gradient elution from $70 / 30$ to $60 / 40 \mathrm{~A} / \mathrm{B}$

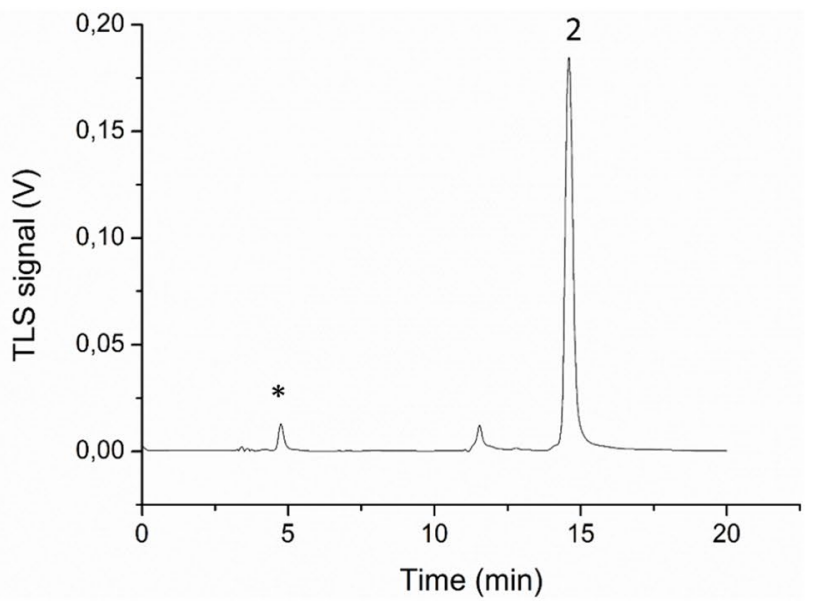

and step gradient elution from $70 / 30$ to $60 / 40 \mathrm{~A} / \mathrm{B}$ after elution of malvidin-3-O-glucoside (marked with asterisk) at 5 min (right). Synthesized malvidin-3-O-glucoside-4-vinylphenol is marked with number 2

for gradient HPLC-DAD method $(7$ and $45 \mu \mathrm{g} / \mathrm{L}$, respectively). Based on the literature data available (Table 1), the HPLC-TLS method shows superior LODs and LOQs to several published HPLC-DAD and HPLC-MS methods (Table 1). Just recent publication from 2020 by Zhang et al. [25] reports about LODs of different wine anthocyanins and pyranoanthocyanins (expressed as mvd-3-glc) below $1 \mu \mathrm{g} / \mathrm{L}$ measured with HPLC-MS/MS, however MS/MS is still not routinely used for monitoring of anthocyanins and pyranoanthocyanins due to the cost. Furthermore, the HPLC-TLS method showed good reproducibility expressed as relative standard deviation of peak area for $1 \mathrm{mg} / \mathrm{L} \mathrm{Mvd-3-glc}$, which was $8.1 \%$. Reproducibility of retention time for $1 \mathrm{mg} / \mathrm{L} \mathrm{Mvd-3-glc}$ was $0.7 \%$. Two HPLC-DAD methods were included in the comparison-gradient HPLC-DAD as for the analysis of pyranoanthocyanins in wines gradient elution is usually
Table 3 Calibration parameters for HPLD-DAD and HPLC-TLS methods

\begin{tabular}{|c|c|c|c|}
\hline Method & Gradient HPLC-DAD & Isocratic HPLC-DAD & HPLC-TLS \\
\hline Wavelength [nm] & 520.0 & 514.5 & 514.5 \\
\hline Injection volume $[\mu \mathrm{L}]$ & 40 & 20 & 20 \\
\hline Linearity range $[\mathrm{mg} / \mathrm{L}]$ & $0.100-500$ & $0.500-500$ & $0.025-10$ \\
\hline Slope [k] & 4.31 & 2.29 & 0.010 \\
\hline Intercept $[\mathrm{n}]^{*}$ & -1.2689 & -0.4247 & 0.0004 \\
\hline $\mathrm{R}^{2}$ & 0.9973 & 0.9979 & 0.9994 \\
\hline $\operatorname{LOD}[\mu \mathrm{g} / \mathrm{L}]$ & 45 & 160 & 7 \\
\hline LOQ $[\mu \mathrm{g} / \mathrm{L}]$ & 140 & 460 & 25 \\
\hline $\begin{array}{l}\text { System precision [RSD-\% using } \\
\text { standard solutions of } 1 \mathrm{mg} / \mathrm{L}]\end{array}$ & 7.1 & 2.2 & 8.1 \\
\hline
\end{tabular}

* The equation $y=k x+n$ is the equation of the calibration curve, where $y$ is the chromatographic peak area, $x$ the concentration of analyte $[\mathrm{mg} / \mathrm{L}], \mathrm{k}$ is the slope of the curve and $\mathrm{n}$ is the intercept 
applied [14, 20, 21], and HPLC-DAD performed under the same conditions as HPLC-TLS method (detection wavelength, step gradient elution, injection volume). In the gradient HPLC-DAD the injection volume was higher as, higher injection volume results in the better sensitivity of the method (lower LOD) $[66,67]$. For Mvd3-glc HPLC-DAD with step gradient elution provided LOD and LOQ 3-times higher compared to continuous
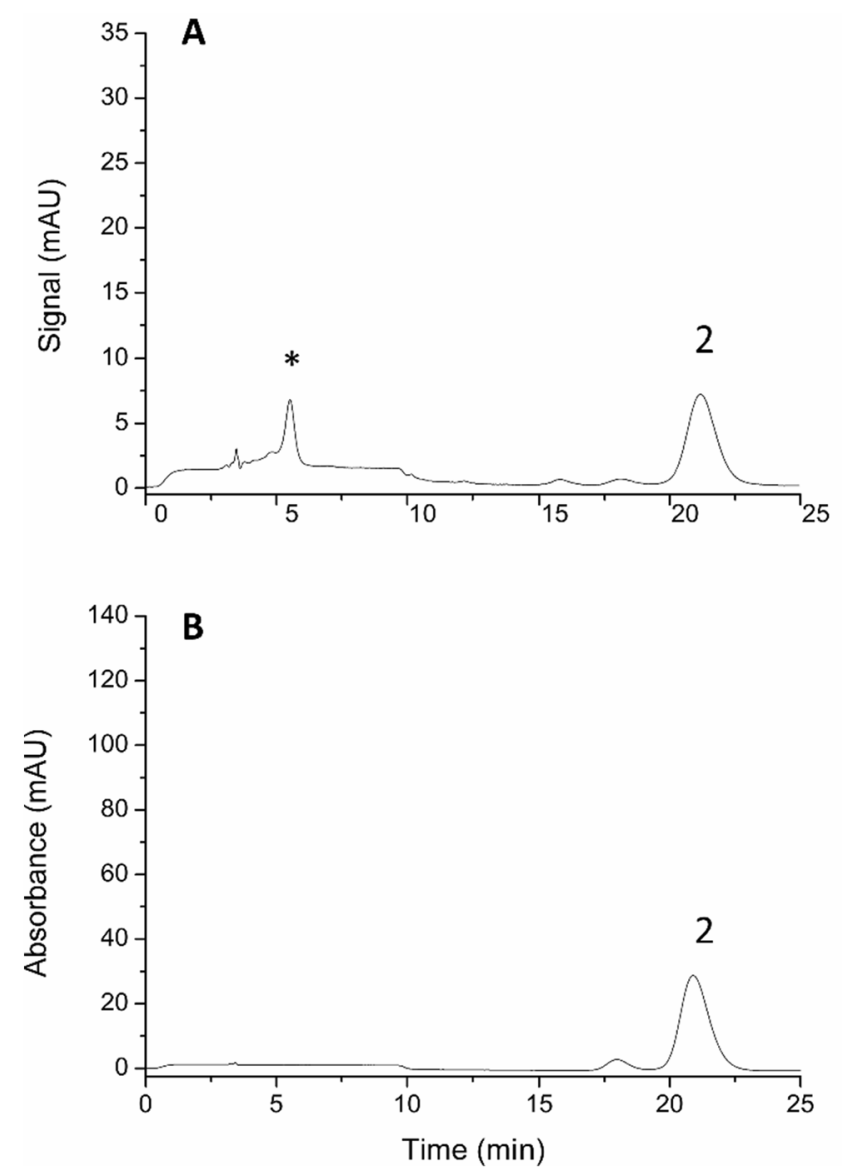

Fig. 6 HPLC-DAD chromatograms of isolated malvidin-3-O-glucoside-4-vinylphenol standard (Fig. 6a) and synthesized malvidin-3-Oglucoside-4-vinylphenol in synthetic wine sample (Fig. 6b) that was supplemented with $50 \mathrm{mg} / \mathrm{L}$ of malvidin-3-O-glucoside (marked with asterisk) and $100 \mathrm{mg} / \mathrm{L} p$-coumaric acid and fermented with commercial FPC yeast. Malvidin-3-O-glucoside-4-vinylphenol is gradient elution HPLC-DAD. Furthermore, the signal of the pyranoanthocyanin Mvd-3-glc-4-VP was four times higher either for pure standard or for pyranoanthocyanins formed in synthetic wine fermented with commercial FPC yeast (Fig. 6). As gradient HPLC-DAD showed superior sensitivity and lower LOD, it was selected for further method comparisons with HPLC-TLS (Table 4).
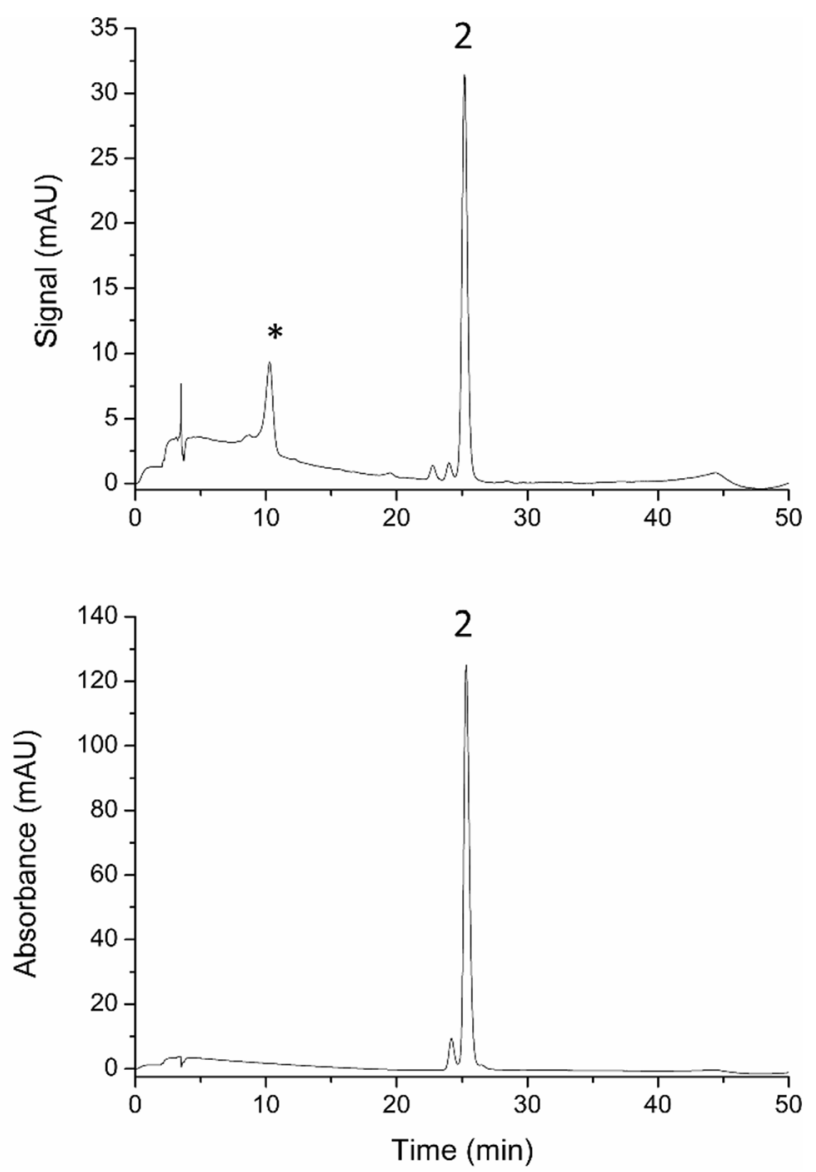

marked with number 2. Information about identification of the peak is presented in the Table 3. Samples were analyzed with HPLC-DAD step gradient method with the same conditions as in HPLC-TLS method and with gradient HPLC-DAD method. As gradient HPLC-DAD method showed better sensitivity it was selected for future comparison with HPLC-TLS method

Table 4 MS data, $\lambda_{\max }$ and HPLC-TLS chromatogram characteristics (retention time) for isolated vinylphenolic pyranoanthocyanins

\begin{tabular}{|c|c|c|c|c|c|c|}
\hline Peak & Compound & $\mathrm{t}_{\mathrm{r}} \mathrm{HPLC} \mathrm{TLS}^{*}[\mathrm{~min}]$ & $\mathrm{MS}[\mathrm{m} / \mathrm{z}]$ & MS/MS & MS/MS/MS & $\lambda_{\max }[\mathrm{nm}]$ \\
\hline 1 & Malvidin-3-glucoside-4-vinylcaffeoyl (Pinotin A) & $14.1 \pm 0.1[0.4 \%]$ & 625 & 463 & $463,447,402$ & 509 \\
\hline 2 & Malvidin-3-glucoside-4-vinylphenol & $15.1 \pm 0.1[0.4 \%]$ & 609 & 447 & $447,431,414$ & 502 \\
\hline 3 & Malvidin-3-glucoside-4-vinylguaiacol & $16.3 \pm 0.1[0.8 \%]$ & 639 & 477 & $477,462,416$ & 510 \\
\hline
\end{tabular}

*The average retention time $[\mathrm{N}=6]$. In brackets the RSD of retention time of pyranoanthocyanins is shown. $\mathrm{MS}^{\mathrm{n}}$ fragments of isolated pyranoanthocyanins are shown in the supplementary information 


\subsection{Application of HPLC-TLS in the monitoring of vinylphenolic production during fermentation in synthetic grape must supplemented with Pinot Noir skin extract and $50 \mathrm{mg} / \mathrm{L} p$-coumaric acid}

Formation of vinylphenolic pyranoanthocyanins in synthetic grape must, supplemented with Pinot Noir skin extract and fermented with commercial S. cerevisiae FPC yeast strain was monitored with HPLC-TLS. Sampling took place at day 2 and day 10 of the fermentation (Fig. 7). The sample is more complex than the one containing only malvidin-3-O-glucoside as a substrate source of anthocyanins in pyranoanthocyanin biosynthesis and better represents the complexity of wine matrix as red grapes contain substantial amounts of mostly monomeric anthocyanins, i.e. -3-O-monoglucosides of delphinidin, cyanidin, petunidin, peonidin and malvidin, with latter being present in the highest concentrations $[29,68]$. The results showed that formation of vinylphenolic pyranoanthocyanin Mvd-4-VP occurs already the second day of fermentation, with the concentration $0.8 \pm 0.0 \mathrm{mg} / \mathrm{L}$. The concentration of Mvd4-VP increased till the end of fermentation by almost a factor of $10-7.6 \pm 0.5 \mathrm{mg} / \mathrm{L}$, which can be seen from the Fig. 7 . With the increase in Mvd-4-VP concentration, the decrease in anthocyanin concentration was also observed. It has been previously reported that the reaction between Mvd3-glc and 4-vinylphenol occurs quickly in synthetic media, especially with substrate being present in high concentrations, such as $2000 \mathrm{mg} / \mathrm{L}[69,70]$. The concentration of anthocyanins in Pinot Noir skin extract in our medium was

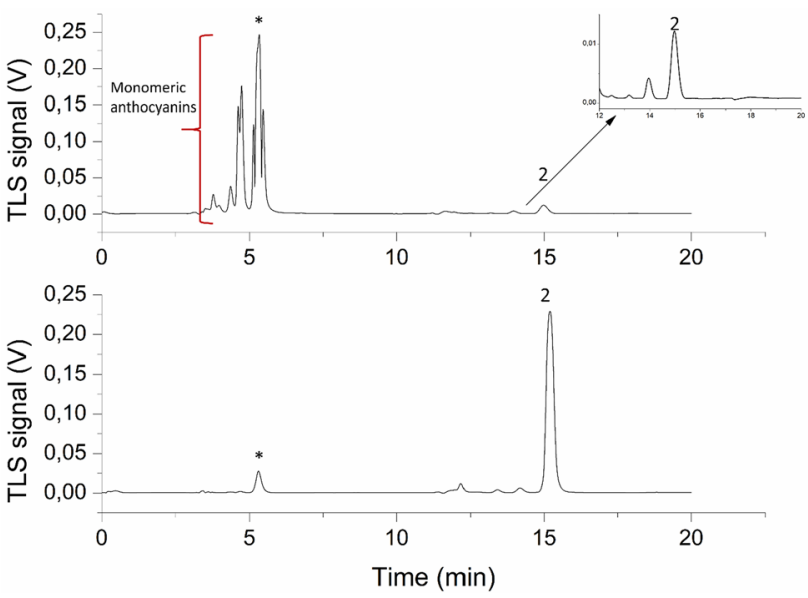

Fig. 7 HPLC-TLS chromatograms of synthetic wines supplemented with Pinot Noir skin extract and $50 \mathrm{mg} / \mathrm{L}$ of $p$-coumaric acid and fermented with commercial S. cerevisiae FPC yeast. Upper chromatogram shows wine sampled at day 2 of fermentation and lower chromatogram shows wine sampled at day 10 of fermentation. Malvidin-3-O-glucoside is marked with asterisk, and malvidin-3-Oglucoside-4-vinylphenol is marked with number 2
$93 \mathrm{mg} / \mathrm{L}$. However, the concentration of $p$-coumaric acid in grapes and wines is usually in $\mu \mathrm{g} / \mathrm{L}$ to low $\mathrm{mg} / \mathrm{L}$ range [71], highlighting the importance of implementing HPLC-TLS in yeast characterization in real fermentation samples, due to superior sensitivity compared to conventional HPLC-DAD method, which is important in yeast starter selection and yeast optimization studies with micro-vinifications using microtiter plates, where small sample volume is required.

\subsection{The monitoring of the vinylphenolic pyranoanthocyanins evolution during fermentation of Pinot Noir grapes}

Lab-scale fermentations were carried out either as sequential fermentation of two non-Saccharomyces strains with high HCDC activity (P. guilliermondii ZIM624 and W. anomalus $\mathrm{S138)}$ and $S$. cerevisiae strain or as single fermentations with S. cerevisiae strains (FPC, ZIM2180). The reason behind the fermentations was testing of the developed HPLC-TLC technique in real wine chemistry experiment. At the completion of fermentations, we have confirmed the formation of three main vinylphenolic pyranoanthocyanins during fermentation; malvidin-3-O-glucoside-4-vinylcaffeoyl (Pinotin A), Mvd-4-VP and malvidin-3-O-glucoside-4-vinylguaiacol (Mvd-4-VG), with Mvd-4-VP formed in the highest concentration, followed by Mvd-4-VG and Pinotin A employing the HPLC-TLS. Identification of individual pyranoanthocyanins was based in comparison of retention times to retention times of synthetic standards. The trend of pyranoanthocyanin concentrations was observed in all of the six fermentations.

The formation of Mvd-4-VP and Mvd-4-VG was detected on the 7th day of fermentation with HPLC-TLS technique, although the concentrations were below calculated LOD (Table 2). With HPLC-DAD method it was possible to observe vinylphenolic pyranoanthocyanin formation 5 days later, on the $12^{\text {th }}$ day of the fermentation. Mvd-4-VP and Mvd-4-VG were detected, although their concentration was below calculated LOD (Fig. 8). At the end of fermentation all three pyranoanthocyanins were detected with both methods although with HPLC-DAD, Pinotin $A$ was not quantifiable as its concentration was below LOQ of the method (Table 3). With HPLC-TLS, at the end of the fermentation, all three vinylphenolic pyranoanthocyanins were present in the concentration above calculated LOQ $(25 \mu \mathrm{g} / \mathrm{L})$. The Fig. 8 shows only the chromatogram for the sequential fermentation of ZIM624 ( $P$. guilliermondii yeast) with FPC (S. cerevisiae yeast), while similar trend was observed in the profile of synthesized pyranoanthocyanins of other five fermentation experiments (S138 + FPC, ZIM624 + ZIM2180, S138 + ZIM2180, FPC, ZIM2180). The quantification results showed that ZIM624 yeast in sequential fermentation with S. cerevisiae 

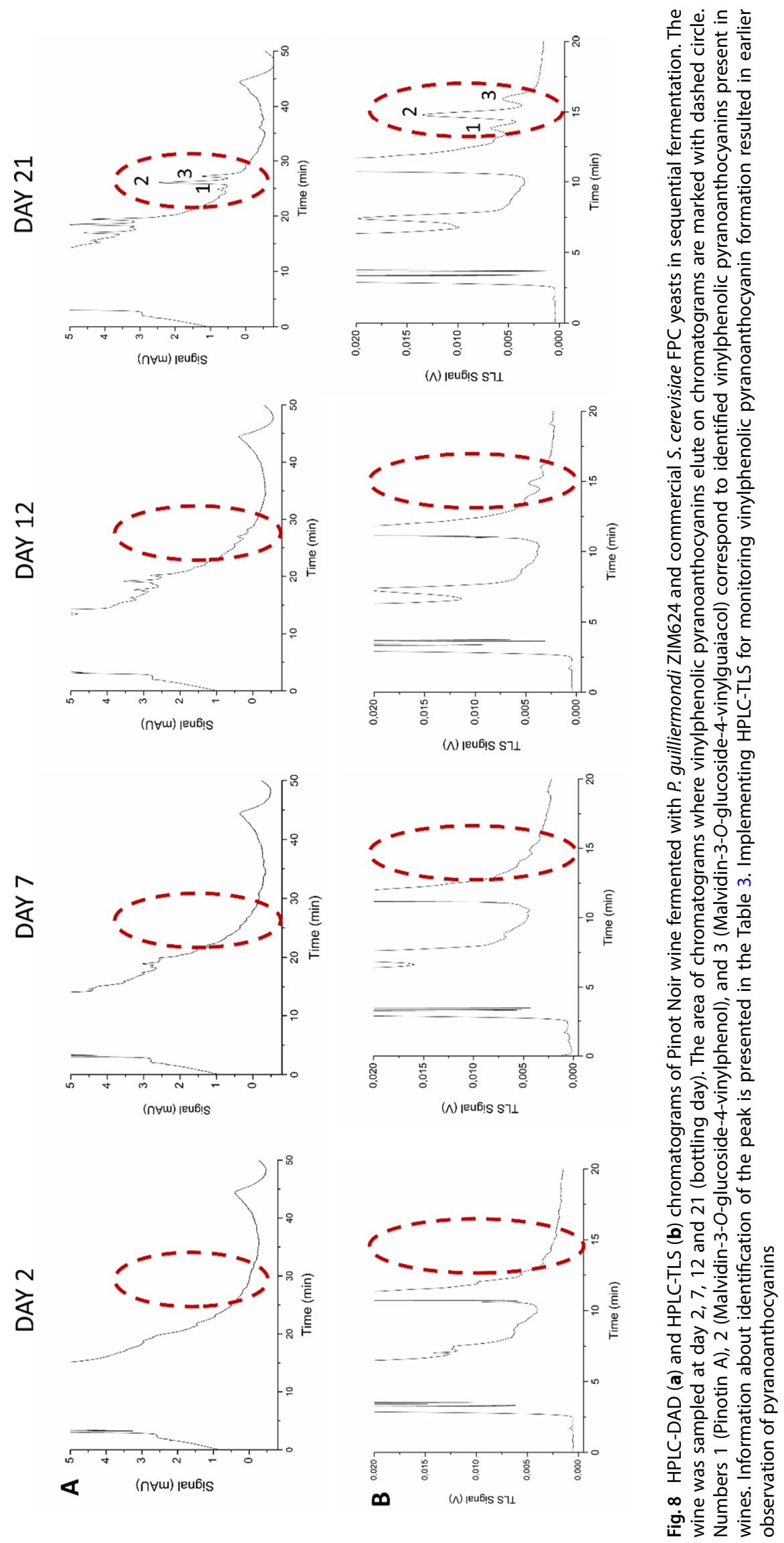
yeast was superior in the amounts of pyranoanthocyanins synthetized. Native S. cerevisiae yeast alone synthesized more pyranoanthocyanins than commercial FPC yeast in both, single or in sequential fermentations. The calculated values for Pinotin A, Mvd-4-VP, and Mvd-4-VG in the case of ZIM624 + FPC sequential fermentation were 5-, 37- and 12 -times above the calculated LOQ of the method. The concentration ranges for six fermentation experiments for Pinotin A, Mvd-4-VP, and Mvd-4-VG were 4- to 9- times, 19- to 65 times, and 8- to 18-times above LOQ, respectively (Additional data about concentrations is shown in the supplementary information). HPLC-TLS has been proven to be more sensitive in the monitoring of pyranoanthocyanin formation compared to used HPLC-DAD methods as pyranoanthocyanins were detected earlier in the fermentation process and all of them could be quantified. Identification of pyranoanthocyanins was carried out with comparison of retention of standards to the ones in the wine samples and with standard addition method where samples was spiked with individual isolated standard, and an increase in the signal of pyranoanthocyanin was observed in the spiked samples.

\section{Conclusions}

HPLC-TLS technique was applied successfully in wine chemistry analysis, for detection and quantification of three vinylphenolic pyranoanthocyanins typical for Pinot Noir wines in real fermentation experiments. We followed six different fermentations employing two native nonSaccharomyces (Pichia guilliermondii ZIM624 and Wickerhamomyces anomalus S138) and two S. cerevisiae strains (commercial FPC and native ZIM2180). Applied analytical techniques enabled us following the synthesis of stabile wine pigments during wine fermentation, as well as comparisons in respect to quantification of produced pigments during and at the end of the fermentation. The highest pyranoanthocyanin concentrations were produced with native ZIM2180 Saccharomyces yeast in the sequential fermentation but also in single strain fermentation compared to the commercial FPC strain. To the best of our knowledge this is the first application of its kind. Although wine is a complex matrix, our results showed better performance of gradient HPLC-TLS method compared to both gradient HPLC-DAD and isocratic HPLC-DAD due to superior sensitivity of the HPLC-TLS method. Because of better sensitivity and lower LODs, the formation of vinylphenolic pyranoanthocyanins could be detected with HPLC-TLS 5 days earlier in fermentation (day 7) compared to the HPLC-DAD technique (day 12 of the fermentation). As wine industry is constantly searching for yeast strains that could improve wines in terms of color, HPLC-TLS technique could provide a useful tool for characterization of wine yeasts with desired enological properties in microvinification testing.

Acknowledgements This work was supported by Slovenian Research Agency (ARRS) by grant for young researchers: ARRS-MR-LP-2017/393 and research programme P1-0034; Analytics and Chemical Characterization of Materials and Processes (2009-2019).

\section{Compliance with ethical standards}

Conflict of interest On behalf of all authors, the corresponding author states that there is no conflict of interest.

\section{References}

1. Alcalde-Eon C, Escribano-Bailón MT, Santos-Buelga C, RivasGonzalo JC (2006) Changes in the detailed pigment composition of red wine during maturity and ageing: a comprehensive study. Anal Chim Acta 563:238-254

2. He F, Liang NN, Mu L et al (2012) Anthocyanins and their variation in red wines II. Anthocyanin derived pigments and their color evolution. Molecules 17:1483-1519. https://doi. org/10.3390/molecules17021483

3. Benucci I, Cerreti M, Liburdi K et al (2018) Pre-fermentative cold maceration in presence of non-Saccharomyces strains: evolution of chromatic characteristics of Sangiovese red wine elaborated by sequential inoculation. Food Res Int 107:257-266. https:// doi.org/10.1016/j.foodres.2018.02.029

4. Morata A, Gómez-Cordovés MC, Colomo B, Suárez JA (2005) Cell wall anthocyanin adsorption by different Saccharomyces strains during the fermentation of Vitis vinifera L. cv Graciano grapes. Eur Food Res Technol 220:341-346. https://doi.org/10.1007/ s00217-004-1053-8

5. Cliff MA, King MC, Schlosser J (2007) Anthocyanin, phenolic composition, colour measurement and sensory analysis of $B C$ commercial red wines. Food Res Int 40:92-100. https://doi. org/10.1016/j.foodres.2006.08.002

6. Carew AL, Smith P, Close DC et al (2013) Yeast effects on Pinot noir wine phenolics, color, and tannin composition. J Agric Food Chem 61:9892-9898. https://doi.org/10.1021/jf4018806

7. Carew AL, Close DC, Dambergs RG (2015) Yeast strain affects phenolic concentration in Pinot noir wines made by microwave maceration with early pressing. J Appl Microbiol 118:1385-1394. https://doi.org/10.1111/jam.12785

8. Caridi A, De Bruno A, De Salvo E et al (2017) Selected yeasts to enhance phenolic content and quality in red wine from low pigmented grapes. Eur Food Res Technol 243:367-378. https:// doi.org/10.1007/s00217-016-2750-9

9. De Freitas V, Mateus N (2011) Formation of pyranoanthocyanins in red wines: a new and diverse class of anthocyanin derivatives. Anal Bioanal Chem 401:1467-1477

10. Bautista-Ortín AB, Romero-Cascales I, Fernández-Fernández $\mathrm{Jl}$ et al (2007) Influence of the yeast strain on Monastrell wine colour. Innov Food Sci Emerg Technol 8:322-328. https://doi. org/10.1016/j.ifset.2007.03.005

11. Suárez-Lepe JA, Morata A (2012) New trends in yeast selection for winemaking. Trends Food Sci Technol 23:39-50. https://doi. org/10.1016/j.tifs.2011.08.005

12. Morata A, González C, Suárez-Lepe JA (2007) Formation of vinylphenolic pyranoanthocyanins by selected yeasts fermenting red grape musts supplemented with 
hydroxycinnamic acids. Int J Food Microbiol 116:144-152. https://doi.org/10.1016/j.ijfoodmicro.2006.12.032

13. Benito S, Morata A, Palomero F et al (2011) Formation of vinylphenolic pyranoanthocyanins by Saccharomyces cerevisiae and Pichia guilliermondii in red wines produced following different fermentation strategies. Food Chem 124:15-23. https ://doi.org/10.1016/j.foodchem.2010.05.096

14. Morata A, Benito S, Loira I et al (2012) Formation of pyranoanthocyanins by Schizosaccharomyces pombe during the fermentation of red must. Int J Food Microbiol 159:47-53. https ://doi.org/10.1016/j.ijfoodmicro.2012.08.007

15. Morata A, Loira I, Heras JM et al (2016) Yeast influence on the formation of stable pigments in red winemaking. Food Chem 197:686-691. https://doi.org/10.1016/j.foodchem.2015.11.026

16. Del Fresno JM, Morata A, Loira I et al (2017) Use of non-Saccharomyces in single-culture, mixed and sequential fermentation to improve red wine quality. Eur Food Res Technol 243:21752185. https://doi.org/10.1007/s00217-017-2920-4

17. Medina K, Boido E, Dellacassa E, Carrau F (2018) Effects of non-Saccharomyces yeasts on color, anthocyanin, and anthocyanin-derived pigments of Tannat grapes during fermentation. Am J Enol Vitic 69:148-156. https://doi.org/10.5344/ ajev.2017.17055

18. Fleet GH (2008) Wine yeasts for the future. FEMS Yeast Res 8:979-995. https://doi.org/10.1111/j.1567-1364.2008.00427.x

19. Roman T, Barp L, Malacarne M et al (2019) Mono- and diglucoside anthocyanins extraction during the skin contact fermentation in hybrid grape varieties. Eur Food Res Technol 245:2373-2383. https://doi.org/10.1007/s00217-019-03355-4

20. Shim YS, Kim S, Seo D et al (2014) Rapid method for determination of anthocyanin glucosides and free delphinidin in grapes using u-HPLC. J Chromatogr Sci 52:629-635. https:// doi.org/10.1093/chromsci/bmt091

21. Arapitsas P, Perenzoni D, Nicolini G, Mattivi F (2012) Study of sangiovese wines pigment profile by UHPLC-MS/MS. J Agric Food Chem 60:10461-10471. https://doi.org/10.1021/jf302 617 e

22. Loira I, Morata A, Comuzzo P et al (2015) Use of Schizosaccharomyces pombe and Torulaspora delbrueckii strains in mixed and sequential fermentations to improve red wine sensory quality. Food Res Int 76:325-333. https://doi.org/10.1016/j.foodr es.2015.06.030

23. Escott C, Del Fresno JM, Loira I et al (2018) Formation of polymeric pigments in red wines through sequential fermentation of flavanol-enriched musts with non-Saccharomyces yeasts. Food Chem 239:975-983. https://doi.org/10.1016/j.foodc hem.2017.07.037

24. Trikas ED, Melidou M, Papi RM et al (2016) Extraction, separation and identification of anthocyanins from red wine by-product and their biological activities. J Funct Foods 25:548-558. https ://doi.org/10.1016/j.jff.2016.06.033

25. Zhang XK, Li SY, Zhao X et al (2020) HPLC-MS/MS-based targeted metabolomic method for profiling of malvidin derivatives in dry red wines. Food Res Int 134:109226. https://doi.org/10.1016/j. foodres.2020.109226

26. Trošt K, Klančnik A, Mozetič Vodopivec B et al (2016) Polyphenol, antioxidant and antimicrobial potential of six different white and red wine grape processing leftovers. J Sci Food Agric 96:4809-4820. https://doi.org/10.1002/jsfa.7981

27. Bernardi T, Bortolini O, Massi A et al (2019) Exploring the synergy between HPTLC and HPLC-DAD for the investigation of wine-making by-products. Molecules 24:3416. https://doi. org/10.3390/molecules24193416

28. Flamini $R$ (2003) Mass spectrometry in grape and wine chemistry. Part I: Polyphenols. Mass Spectrom Rev 22:218-250. https ://doi.org/10.1002/mas.10052
29. Lorrain B, Ky I, Pechamat L, Teissedre PL (2013) Evolution of analysis of polyhenols from grapes, wines, and extracts. Molecules 18:1076-1100. https://doi.org/10.3390/molecules 1 8011076

30. Martelanc M, Žiberna L, Passamonti S, Franko M (2014) Direct determination of free bilirubin in serum at sub-nanomolar levels. Anal Chim Acta 809:174-182. https://doi.org/10.1016/j. aca.2013.11.041

31. Martelanc M, Žiberna L, Passamonti S, Franko M (2016) Application of high-performance liquid chromatography combined with ultra-sensitive thermal lens spectrometric detection for simultaneous biliverdin and bilirubin assessment at trace levels in human serum. Talanta 154:92-98. https://doi.org/10.1016/j. talanta.2016.03.053

32. Gordon JP, Leite RCC, Moore RS et al (1964) Long-transient effects in lasers with inserted liquid samples. Bull Am Phys Soc 9:501-509. https://doi.org/10.1063/1.1713919

33. Badran HA (2015) Thermal properties of a new dye compound measured by thermal lens effect and Z-scan technique. Appl Phys B Lasers Opt 119:319-326. https://doi.org/10.1007/s0034 0-015-6068-2

34. Singhal S, Goswami D (2019) Thermal lens study of NIR femtosecond laser-induced convection in alcohols. ACS Omega 4:1889-1896. https://doi.org/10.1021/acsomega.8b02956

35. Shokoufi N, Atrabi RJ, Kargosha K (2014) Laser-induced thermal lens spectrometry after cloud point extraction for trace analysis of mercury in water and drug samples. J Anal Sci Technol 5:39. https://doi.org/10.1186/s40543-014-0039-9

36. Kazemi E, Dadfarnia S, Haji Shabani AM et al (2016) Iron oxide functionalized graphene oxide as an efficient sorbent for dispersive micro-solid phase extraction of sulfadiazine followed by spectrophotometric and mode-mismatched thermal lens spectrometric determination. Talanta 147:561-568. https://doi. org/10.1016/j.talanta.2015.10.033

37. Cabrera H, Akbar J, Korte D et al (2018) Trace detection and photothermal spectral characterization by a tuneable thermal lens spectrometer with white-light excitation. Talanta 183:158-163. https://doi.org/10.1016/j.talanta.2018.02.073

38. Cabrera H, Goljat L, Korte D et al (2020) A multi-thermal-lens approach to evaluation of multi-pass probe beam configuration in thermal lens spectrometry. Anal Chim Acta 1100:182-190. https://doi.org/10.1016/j.aca.2019.12.009

39. Galimova VR, Liu M, Franko M et al (2018) Hemichrome determination by thermal lensing with polyethylene glycols for signal enhancement in aqueous solutions. Anal Lett 51:1743-1762. https://doi.org/10.1080/00032719.2017.1391828

40. Tomsič G, Goljat L, Budasheva $\mathrm{H}$ et al (2019) Determination of iron in environmental water samples by FIA-TLS. Acta Chim Slov. https://doi.org/10.17344/acsi.2018.4825

41. Korte D, Grahovac A, Jerkic A et al (2017) Speciation and determination of ionic and trace-level colloidal silver in selected personal care products by thermal lens spectrometry. Pharm Anal Acta. https://doi.org/10.4172/2153-2435.1000573

42. Rivoira L, Žorž M, Martelanc M et al (2017) Novel approaches for the determination of biogenic amines in food samples. Studia Univ Babeş-Bolyai. Chemia 62(3):103-122. https://doi. org/10.24193/subbchem.2017.3.08

43. Ziberna L, Martelanc M, Franko M, Passamonti S (2016) Bilirubin is an endogenous antioxidant in human vascular endothelial cells. Sci Rep 6:1-6. https://doi.org/10.1038/srep29240

44. Liu M, Malovrh S, Franko M (2016) Microfluidic flow-injection thermal-lens microscopy for high-throughput and sensitive analysis of sub- $\mu \mathrm{L}$ samples. Anal Methods 8:5053-5060. https ://doi.org/10.1039/c6ay00932h 
45. Liu M, Franko M (2016) Thermal lens spectrometry: still a technique on the horizon? Int J Thermophys 37:67. https://doi. org/10.1007/s10765-016-2072-y

46. Franko M, Liu M, Boškin A et al (2016) Fast screening techniques for neurotoxigenic substances and other toxicants and pollutants based on thermal lensing and microfluidic chips. Anal Sci 32:23-30. https://doi.org/10.2116/analsci.32.23

47. Franko M (2008) Thermal lens spectrometric detection in flow injection analysis and separation techniques. Appl Spectrosc Rev 43:358-388. https://doi.org/10.1080/05704920802108032

48. Franko M, Sikovec M, Kozar-Logar J, Bicanic D (2001) Thermal lens spectrometry in food analysis and environmental research. Anal Sci 17:515-518. https://doi.org/10.1016/j.emc.2009.09.002

49. Logar JK, Šikovec M, Malej A, Franko M (2002) The effects of eluent mixing on TLS detection in gradient elution HPLC. Anal Bioanal Chem 374:323-328. https://doi.org/10.1007/s0021 6-002-1470-0

50. Kožar Logar J, Franko M (2003) The effects of eluent's optothermal parameters on TLS detection in gradient HPLC. Rev Sci Instrum 74:300-302. https://doi.org/10.1063/1.1515899

51. Franko M, Van De Bovenkamp P, Bicanic D (1998) Determination of trans- $\beta$-carotene and other carotenoids in blood plasma using high-performance liquid chromatography and thermal lens detection. J Chromatogr B Biomed Appl 718:47-54. https ://doi.org/10.1016/S0378-4347(98)00347-8

52. Luterotti S, Franko M, Bicanic D (1999) Ultrasensitive determination of $\beta$-carotene in fish oil-based supplementary drugs by HPLC-TLS. J Pharm Biomed Anal 21:901-909. https://doi. org/10.1016/S0731-7085(99)00185-5

53. Luterotti S, Franko M, Šikovec M, Bicanic D (2002) Ultrasensitive assays of trans- and cis- $\beta$-carotenes in vegetable oils by highperformance liquid chromatography - thermal lens detection. Anal Chim Acta 460:193-200. https://doi.org/10.1016/S0003 -2670(02)00228-3

54. Topić Božič J, Butinar L, Albreht A et al (2020) The impact of Saccharomyces and non-Saccharomyces yeasts on wine colour: a laboratory study of vinylphenolic pyranoanthocyanin formation and anthocyanin cell wall adsorption. LWT 123:109072. https:// doi.org/10.1016/j.lwt.2020.109072

55. Henscke PA, Jiranek V (2002) Yeast-metabolism of nitrogen compounds. In: Fleet GH (ed) Wine microbiology and biotechnology. Taylor \& Francis, New York, pp 77-165

56. Ribéreau-Gayon $P$, Dubourdieu $D$, Donèche $B$, Lonvaud $A$ (2006) Red winemaking. In: Ribereau-Gayon P (ed) Handbook of enology. Wiley, Chichester, pp 327-395

57. Topić Božič J, Curko N, Kovačević Ganić K et al (2020) Synthesis of pyranoanthocyanins from Pinot Noir grape skin extract using fermentation with high pyranoanthocyanin producing yeasts and model wine storage as potential approaches in the production of stable natural food colorants. Eur Food Res Technol. https ://doi.org/10.1007/s00217-020-03467-2

58. Snook RD, Lowe RD (1995) Thermal lens spectrometry. A review. Analyst 120:2051. https://doi.org/10.1039/an9952002051

59. Dovichi NJ, Harris JM (1979) Laser induced thermal lens effect for calorimetric trace analysis. Anal Chem 51:728-731. https:// doi.org/10.1021/ac50042a034
60. Bialkowski S (1996) Photothermal spectroscopy methods for chemical analysis. Wiley, Hoboken

61. Žorž Furlan M (2018) The detection and study of biologically active compounds in environmental processes. Dissertation, University of Nova Gorica

62. Georges J (1999) Advantages and limitations of thermal lens spectrometry over conventional spectrophotometry for absorbance measurements. Talanta 48:501-509. https://doi. org/10.1016/S0039-9140(98)00242-2

63. Georges J (2008) Matrix effects in thermal lens spectrometry: influence of salts, surfactants, polymers and solvent mixtures. Spectrochim Acta Part A Mol Biomol Spectrosc 69:1063-1072. https://doi.org/10.1016/j.saa.2007.07.062

64. Franko M, Tran CD (2010) Thermal lens spectroscopy. In: Meyers RA (ed) Encyclopedia of analytical chemistry. Wiley, Hoboken, pp 1-32. https://doi.org/10.1002/9780470027318.a9079

65. ICH (2005) ICH topic Q2 (R1) validation of analytical procedures: text and methodology. European Medicines Agency, June 1995 CPMP/ICH/381/95. https://www.ema.europa.eu/en/documents/ scientific-guideline/ich-q-2-r1-validation-analytical-procedures -text-methodology-step-5_en.pdf

66. Karger BL, Martin M, Guiochon G (1974) Role of column parameters and injection volume on detection limits in liquid chromatography. Anal Chem 46:1640-1647. https://doi.org/10.1021/ ac60348a053

67. Boonen J, D'Hondt M, Veryser L et al (2013) A critical quality parameter in quantitative fused-core chromatography: the injection volume. J Pharm Anal 3:330-334. https://doi. org/10.1016/j.jpha.2013.02.002

68. Fernandes A, Oliveira J, Teixeira $\mathrm{N}$ et al (2017) A review of the current knowledge of red wine colour. J Int des Sci la Vigne du Vin 51:1-21. https://doi.org/10.20870/oeno-one.2017.51.1.1604

69. Fulcrand H, Cameira Dos Santos PJ, Sarni-Manchado P et al (1996) Structure of new anthocyanin-derived wine pigments. J Chem Soc Perkin Trans 1:735-739. https://doi.org/10.1039/ p19960000735

70. Sarni-Manchado P, Fulcrand H, Souquet JM et al (1996) Stability and color of unreported wine anthocyanin-derived pigments. J Food Sci 61:938-941. https://doi.org/10.1111/j.1365-2621.1996. tb10906.x

71. Gomez-Alonso S, Garclá-Romero E, Hermosı-Gutierez I et al (2007) HPLC analysis of diverse grape and wine phenolics using direct injection and multidetection by DAD and fluorescence. J Food Compos Anal 20:618-626. https://doi.org/10.1016/j. jfca.2007.03.002

Publisher's Note Springer Nature remains neutral with regard to jurisdictional claims in published maps and institutional affiliations. 